Article

\title{
A Grounded Theory Exploration of Language Massive Open Online Courses (LMOOCs): Understanding Students' Viewpoints
}

\author{
Robert Li-Wei Hsu (D)
}

check for updates

Citation: Hsu, R.L.-W. A Grounded Theory Exploration of Language Massive Open Online Courses (LMOOCs): Understanding Students' Viewpoints. Sustainability 2021, 13, 2577. https://doi.org/10.3390/su 13052577

Academic Editor: Jin Su Jeong

Received: 21 January 2021

Accepted: 22 February 2021

Published: 28 February 2021

Publisher's Note: MDPI stays neutral with regard to jurisdictional claims in published maps and institutional affiliations.

Copyright: (C) 2021 by the author Licensee MDPI, Basel, Switzerland. This article is an open access article distributed under the terms and conditions of the Creative Commons Attribution (CC BY) license (https:/ / creativecommons.org/licenses/by/ $4.0 /)$.
Graduate Program of Hospitality Management, School of Hospitality Management, National Kaohsiung University of Hospitality and Tourism, Kaohsiung City 81271, Taiwan; liweihsu@mail.nkuht.edu.tw

\begin{abstract}
Massive open online courses (MOOCs) have been called the biggest innovation in education in 200 years for their unique attribute of being open and free to any individual with Internet access; however, their high dropout rate has led many people to be concerned or dubious about their effectiveness and applicability. The applicability of MOOCs in English for specific purposes (ESP) courses (in this case, hospitality English) needs more empirical evidence; the present study intends to help fill this gap and extend our current understanding of this issue. This study followed a grounded theory methodology to develop a theoretical model based on a constant dialogue between collected data and the literature. The results suggest that most participants had positive perceptions of language MOOCs (LMOOCs) in general, but some doubted their applicability. Most participants said they would continue to use LMOOCs for learning, depending on the attributes of specific courses. Based on the extracted data, a conceptual model for the applicability of LMOOCs is proposed.
\end{abstract}

Keywords: language massive open online course (LMOOC); grounded theory; affordance; functionality; flexibility; convenience; hospitality English; English for specific purposes (ESP)

\section{Introduction}

Web-based learning has indeed engendered a brand-new paradigm for teaching and learning [1-3]. Scholars such as Jones et al. [4] and Shadiev et al. [5] postulate that students' analytic and interpersonal skills can be enhanced through socialization or cooperative learning in virtual environments [6]. Massive online open courses (MOOCs) are one innovative product of these technological and educational developments, in which course design mentality has shifted from being curriculum oriented to experience oriented [7]. Despite the fact that MOOCs have been used worldwide, the number of language learners who adopt them for learning remains limited [8] because only a handful of MOOCs are specifically designed for language learning and teaching [9]. In the field of language education research, pertinent studies on MOOCs are rather sparse [10]; to extend our current understanding of the effectiveness of language MOOCs (LMOOCs), more empirical evidence is needed to serve as a rationale for future application.

MOOCs have been described as "the biggest innovation to happen in education for 200 years" [11] for their unique attribute of being open and free to any individual with Internet access, which allows the courses to be "massive" in terms of the number of students involved [12,13]. However, some scholars, such as Romeo [14] and Jackson [15], have raised concerns about their actual applicability in education. A high dropout rate is a major challenge for all MOOC designers [16-19]. Although it is unsound and unfair to evaluate the quality of a course by completion rate alone, a high dropout rate still leads people to reconsider the applicability of MOOCs $[20,21]$. Hence, it is of great importance to determine the supporting factors to increase the sustainability of MOOCs [22].

In most MOOCs, instruction is usually delivered via video clips, and some activities have peer interaction $[2,23]$. In this sense, it can seem as if the developers have simply 
digitalized education and delivered it through online platforms without deliberating how to encourage learners to continue to participate or how to enhance their motivation for learning [24]. Even so, the affordances of MOOCs_-breaking down limits of time and space and bringing in learners with various cultural, linguistic, and geographic backgrounds into one class through the Internet—can possibly realize social learning and enable learners to more effectively construct their own knowledge. For this reason, it is a topic worthy of researchers' attention, and turning MOOCs into effective tools will enable every learner who is eager to learn to have access to learning materials [17,25], including LMOOCs. The present study was designed to explore the applicability of LMOOCs for English as a foreign language (EFL) learners to learn hospitality English. Three research questions were addressed:

1. How do learners in hospitality English courses perceive their learning experience with LMOOCs?

2. What are their underlying reasons for using LMOOCs for hospitality English?

3. What are the biggest benefits and challenges they have encountered in their experience using LMOOCs for hospitality English?

To answer these questions, this paper first reviews pertinent research. Then, the methodology is described and the results of the study are presented. Then, a conceptual model is developed based on the results, and suggestions for future research and teaching practice are proposed. A brief conclusion follows.

\section{Literature Review}

\subsection{Theory of Social Learning and MOOCs}

It has been postulated that humans can learn new things through observing, understanding, and imitating [26]. The theory of social learning was proposed by Albert Bandura [27]; it posits that learning is a process wherein learners trigger learning mechanisms through observing and imitating others' behaviors or interactions, acquiring new knowledge accordingly. In other words, social learning points out the importance of interactions between peers, with the environment, or both for the initiation of cognitive behavior [28]. Based on this theory, social learning aims to cultivate an individual's active learning habits, so that new knowledge will no longer be learned through a one-way infusion but will be constructed through interactions [29]. The concept of social learning can be suitably implemented via MOOCs in situations where students are able to learn through observing individual or social interactions that respond to the model built by the instructor [30].

With respect to engagement with MOOCs, Hill [31] identified five types of learners. According to their level of engagement, they are no-shows (who register but never log in), observers (who log in and read the materials but never take part in any activities), drop-ins (who occasionally participate in activities), passive participants (who routinely $\log$ in to the course but do not partake in activities), and active participants (who fully engage in the course). Furthermore, Anderson, et al. [32] analyzed learners' engagement patterns in MOOCs with a set of large-scale trace data and proposed a taxonomy of five behavioral patterns corresponding to five types of learners: viewers (who view the MOOC materials and submit few assignments), solvers (who submit assignments for grades but seldom view the lectures), all-rounders (who maintain a balance between viewing the materials and submitting assignments), collectors (who download materials from MOOCs but submit few assignments), and bystanders (who register but seldom engage in course activities). The researchers also emphasized that an individual's engagement in a MOOC is different from engagement in the offline world and stressed that further exploration into the underlying reasons for this disparity was necessary.

In a MOOC, learners with various backgrounds can be placed on the same platform; empirical evidence indicates that if a class is composed of students with different personality traits and learning styles, this will promote learning motivation [33,34]. Furthermore, such socialization enables learners to fortify their knowledge acquisition [35], as captured 
in Vygotsky's "scaffolding" concept, which emphasizes the importance of interactions [36]. This implies that pedagogy should be focused on the issues of why and how individuals learn instead of what they are learning [37]. Importantly, even if learners are not actively involved in the learning process, meaningful learning can still take place [38]. Specifically in the context of MOOCs, learners may be able to match courses to their passive learning style and how they internalize learning content through passively meaningful learning [39].

\subsection{MOOCs for Language Learning (LMOOCs)}

The term "language MOOC" (LMOOC) was coined by Bárcena and Martín-Monje [40] to indicate "dedicated Web-based online courses for second languages with unrestricted access and potentially unlimited participation." As Ding and Shen [41] pointed out, LMOOCs are different from other MOOCs in two aspects. First, LMOOCs offer a greater variety of content, such as topics and learning activities, as well as materials for learning. Another difference concerns the role played by instructional videos in LMOOCs; rather than pre-recorded lectures, videos serve as a vital language source with authenticity for learners' socialization. Perifanou [42] also argued that social interactions and collaborations among learners can be promoted with LMOOCs. Because of these special attributes, learners using LMOOCs engage with them in varying degrees [41]. For example, LMOOC learners tend to disengage selectively from some topics or activities even though they are highly autonomous.

According to Beirne et al. [43], 143 LMOOCs are offered worldwide and the number is still growing. LMOOCs have been deemed as "the most attractive, criticized and polemic of all types of online language courses" [44], and they have attracted increasing attention in the field of language education $[45,46]$. Previous studies on LMOOCs reported both positive and negative comments by students. The most frequently mentioned benefits include flexibility and a stress-free environment. Additionally, learners' communicative competence may be enriched through interactions with others, and LMOOCs are considered to be suitable as the platform [47]. Nonetheless, it still seems challenging to create adequate socialization in the virtual environment [48]. Moreover, as Bárcena et al. [40] pointed out, language learning is rather complex because "it is both skill-based and knowledge-based" and various types of capabilities need to be carefully included in LMOOCs; hence, foreign language may not be an ideal subject for MOOCs. Obstacles still exist and need to be overcome by LMOOC users (including instructors, administrators, and students) [49], and more empirical evidence is needed in order to provide suggestions for the practice of using LMOOCs in language learning and teaching [23].

\section{Methodology}

\subsection{Research Context}

The LMOOC of this study was designed for anyone interested in learning English for a specific purpose, i.e., to work in the airline industry. The title was "English for Airline Cabin Service." Information about this LMOOC was disseminated through the networks of the National Kaohsiung University of Hospitality and Tourism (NKUHT) in Taiwan; additionally, some private aviation training schools also helped to circulate the information to their students. This course was designed and implemented by NKUHT, where the delivery mainframe is housed. This English for Airline Cabin Service LMOOC consisted of three major components: video, grammar, and test (please refer to Figure 1 for details). 


\section{video}

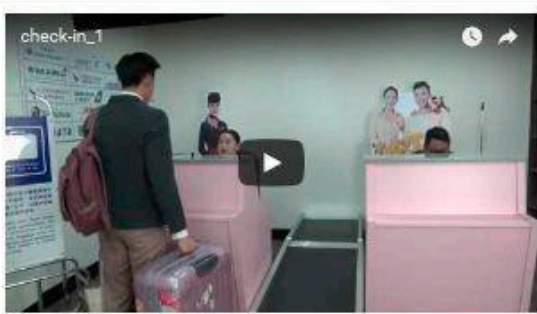

Check

Learn Engleh by video

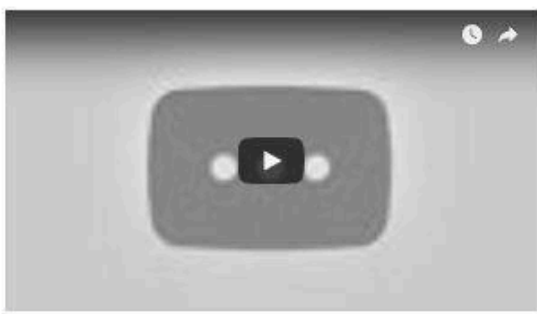

Boarding

Learn English ty video

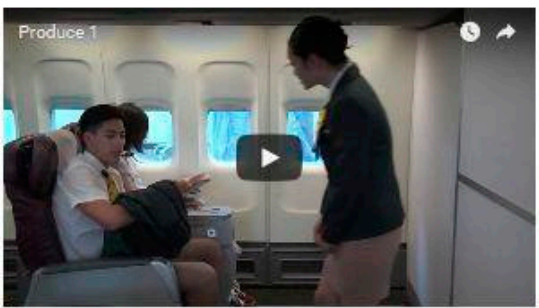

Learn Engish thy videc

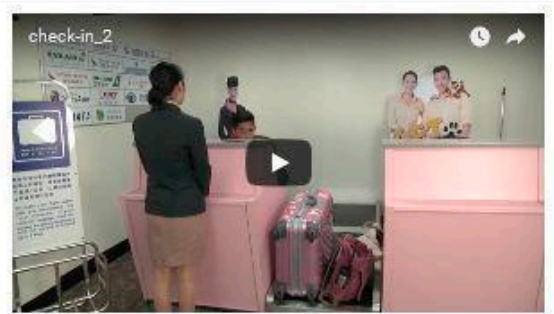

Check

Leam English by video

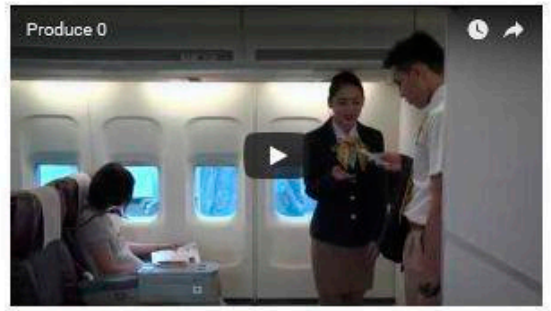

Leam Engish by video

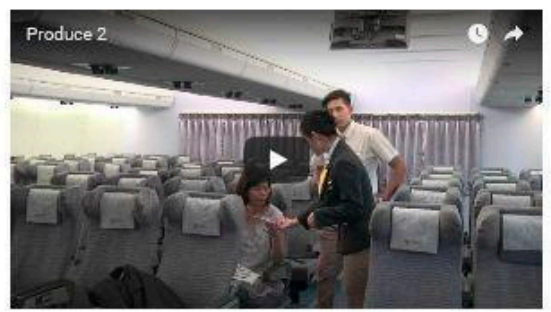

Leam English by video

Figure 1. Video clips of English for Cabin Service.

In addition to these three parts, a forum was also created for interactions, as suggested by Martín-Monje and Barcena [50]. Learners could raise questions about the course content, and their peers who knew the answers could respond. The design and pilot test ran for four months and had good results (e.g., the contents of these LMOOCs were in line with the goal of this course and smoothness of the platform); the course was then ready for learners to register. The course went into operation in February 2019, and after three months of operation, focus groups were convened in order to collect qualitative data to address the research questions. The course lasted for three months, and the last round of interviews was conducted in September 2019.

\subsection{Grounded Theory}

Given both the innovative platform for language learning that LMOOCs provide and the need to address the gap in the literature described above, grounded theory is the appropriate methodological choice [51,52]. Grounded theory is defined as "the discovery of theory from data systematically obtained from social research" [53] (p. 2), which makes it a preferable research method to reflect the ever-changing reality of psychosocial processes [54]. Using grounded theory as the methodology can help to reveal some insights about EFL learners' viewpoints on the applicability of LMOOCs for learning English. Detailed information about the implementation of grounded theory follows below, and the process of data collection, coding, and concept generation is presented in Figure 2. 


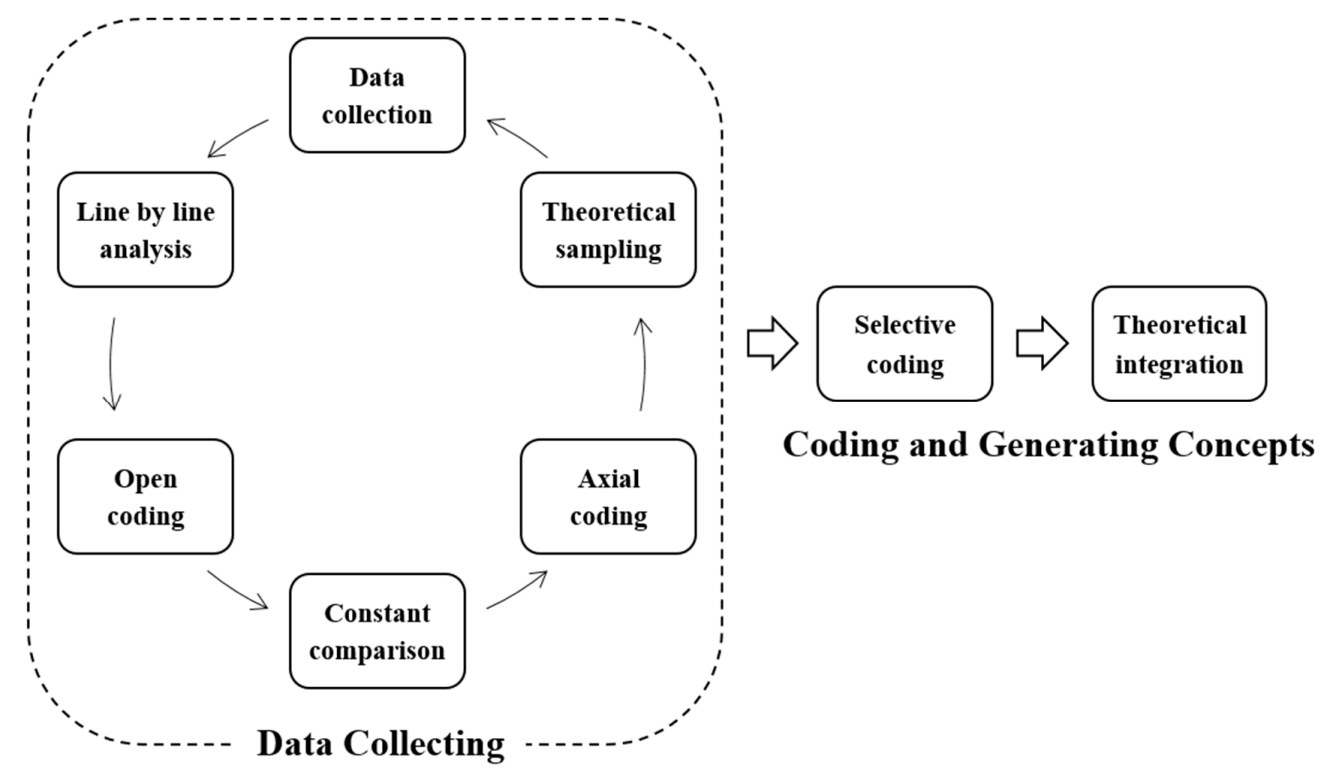

Figure 2. Data collection, coding, and concept generation.

\subsection{Participants}

In keeping with grounded theory, theoretical sampling was administered to "refine ideas, not to increase the size of the original sample" [55] (p. 519). With this goal in mind, three focus groups with five members each were recruited (following a suggestion by Nyumba et al. [56]), for a total of 15 participants. There were 189 learners who registered for this LMOOC, but only 21 completed it, for a completion rate of $11 \%$. These participants were chosen based upon four conditions: geographic location (northern, central, and southern Taiwan), gender (three female and two male participants for each group), and their total login time and login frequency. One aim of this present study is to understand the underlying reasons for EFL learners' willingness to use (or reasons for not using) LMOOCs; hence, one-third of participants' login time fell within one standard deviation of the average length of time $(6.3 \mathrm{~h})$, whereas the remaining two-thirds were equally above and below the interval. Focus group interviews were selected as a means of collecting data because of the group dynamics that arise, which can generate more insightful, richer data in a shorter period of time due to the social interaction among group members [57]. The three groups were formed according to the three metropolitan areas where most of the participants resided (northern, central, and southern Taiwan). All participants consented to take part in the interviews and were informed that they could withdraw from the research if they felt uncomfortable and there would be no penalty. Detailed information about the focus group interviewees is reported in Table 1. More importantly, the number of contacts with each participant and the length of each contact [58] (p. 117) were also captured by the present study.

After the participants were selected, and their informed consent was collected, each was given a code name based on demographic characteristics. For example, a female student from northern Taiwan assigned number 2 was coded as NF2, and a male student from southern Taiwan assigned number 3 was SM3. Additionally, since data collection and analyses were reciprocal, multiple rounds of interviews took place; therefore, another numerical code was given to each piece of collected data according to which interview session it was collected in. Thus, a piece of data collected from a male student from central Taiwan assigned number 1 in the first interview would be CM1-1. 
Table 1. Demographic information of focus groups.

\begin{tabular}{|c|c|c|c|c|c|c|}
\hline Participant & Region & Gender & Code & Age & $\begin{array}{c}\text { Time (Hours) } \\
\text { Using } \\
\text { LMOOCs }\end{array}$ & $\begin{array}{l}\text { Frequency } \\
\text { of LMOOC } \\
\text { Login }\end{array}$ \\
\hline 1 & North & Male & NM1 & 32 & 6.5 & 57 \\
\hline 2 & North & Male & NM2 & 35 & 6.7 & 72 \\
\hline 3 & North & Female & NF3 & 28 & 3.7 & 30 \\
\hline 4 & North & Female & NF4 & 27 & 0.9 & 5 \\
\hline 5 & North & Female & NF5 & 29 & 9.2 & 90 \\
\hline 6 & Central & Female & CF1 & 31 & 1.6 & 18 \\
\hline 7 & Central & Male & CM2 & 25 & 5.1 & 55 \\
\hline 8 & Central & Female & CF3 & 26 & 8.3 & 72 \\
\hline 9 & Central & Female & CF4 & 26 & 7.1 & 81 \\
\hline 10 & Central & Male & CM5 & 24 & 2.6 & 25 \\
\hline 11 & South & Female & SF1 & 27 & 7.6 & 70 \\
\hline 12 & South & Male & SM2 & 31 & 2.2 & 23 \\
\hline 13 & South & Male & SM3 & 35 & 8.9 & 72 \\
\hline 14 & South & Female & SF4 & 26 & 6.1 & 85 \\
\hline 15 & South & Female & SF5 & 25 & $\begin{array}{c}6.5 \\
\text { Mean }=63\end{array}$ & 74 \\
\hline
\end{tabular}

\subsection{Interview Questions}

Chenitz and Swanson [59] suggested that unstructured interviewing should be the norm for data collection based on grounded theory, which was adopted by the present study to acquire data that were not "uncontaminated" by existing theory [60]. Interview questions for this study were mainly derived from three proposed research questions based on a review of relevant literature, but detailed questions were generated based on the interviewer's sensitivity toward the interviewees' responses. According to the principle of theoretical sensitivity, which plays a significant role in grounded theory [61], researchers should enter the research site with profound knowledge about the issues but without preconceived notions [62]. Sample questions included "What do you like and dislike about LMOOCs the most?" and "What is your experience of using LMOOCs?" The iterative nature of grounded theory requires researchers to move between data and emerging theoretical categories; therefore, interview questions were revised according to the responses, or follow-up questions were asked to clarify vague points or interviewees responses [63]. Examples of interview questions developed based on the research questions are presented in Table 2.

Table 2. Research and interview questions.

\begin{tabular}{|c|c|c|}
\hline & Research Questions & Interview Questions \\
\hline 1. & $\begin{array}{l}\text { How do learners in hospitality English } \\
\text { courses perceive their learning } \\
\text { experience with LMOOCs? }\end{array}$ & $\begin{array}{l}\text { - What do you like and dislike about LMOOCs the most? } \\
\text { - What do you think about the applicability of LMOOCs } \\
\text { in learning hospitality English? } \\
\text { - How helpful do you think LMOOCs are to achieve } \\
\text { your learning goal? }\end{array}$ \\
\hline 2. & $\begin{array}{l}\text { What are their underlying reasons for } \\
\text { using LMOOCs to learn hospitality } \\
\text { English? }\end{array}$ & $\begin{array}{l}\text { - Why do you want to register LMOOCs for learning } \\
\text { hospitality English in the first place? } \\
\text { While using LMOOCs for hospitality English learning, } \\
\text { any particular reasons for you to carry on? } \\
\text { After you finish this course, any thoughts about this } \\
\text { experience you can share with us? }\end{array}$ \\
\hline 3. & $\begin{array}{l}\text { What are the biggest benefits and } \\
\text { challenges they have encountered in } \\
\text { their experience using LMOOCs to } \\
\text { learn hospitality English? }\end{array}$ & $\begin{array}{l}\text { - What is your experience of using LMOOCs? } \\
\text { What do you think about the pros and cons of } \\
\text { LMOOCs? } \\
\text { Any suggestions from you to LMOOCs designers to } \\
\text { improve the applicability of LMOOCs? }\end{array}$ \\
\hline
\end{tabular}




\subsection{Data Collection}

This research adopted grounded theory analysis (GTA) to elicit insightful information about students' viewpoints on the applicability of LMOOCs. To ensure the quality of a grounded theory study, which is conducted on the premise of rich, empirical, original, and trustworthy data that can reflect complex psychosocial processes [54], a principle of theoretical saturation is adopted in data collection, which means collecting data until new data do not add more insights [54,64-67].

In this study, a series of focus group interviews was conducted until theoretical saturation was met. Two moderators presided over the interviews to facilitate group interaction and pace the process so all participants would feel at ease and share their viewpoints. With the consent of all participants, interviews were video-recorded, and transcripts were created based on the recordings. Since the transcripts of the first interview were coded, memo writing was used to depict the relationships among concepts. Memos in this context are sense-making tools that inform us of the underlying meanings of codes and further move them to the conceptual level by linking similar points [63]. Detailed information about the iterative process of grounded theory adopted by the present study is given in Figure 3. In total, four rounds of interviews were conducted to reach data saturation.

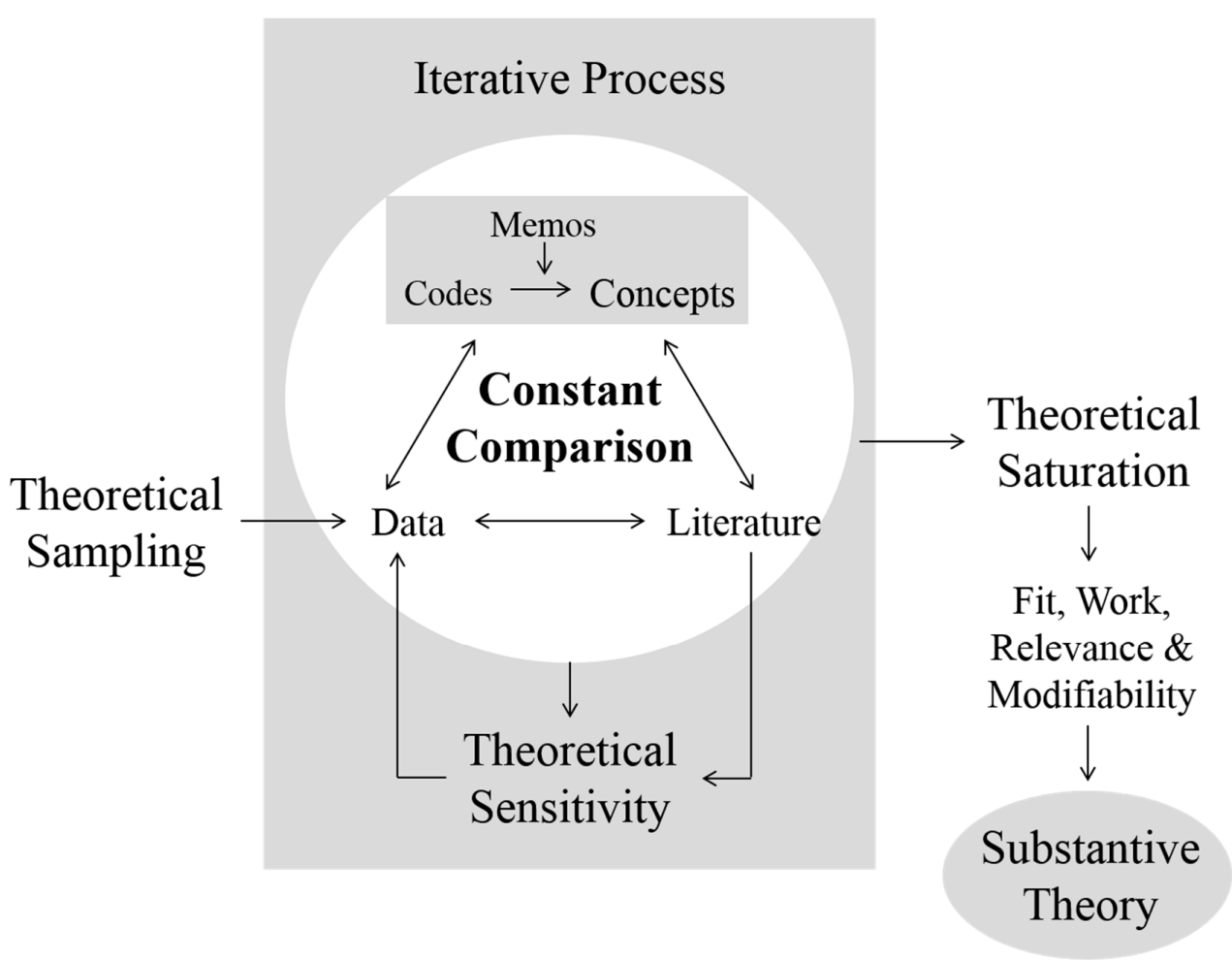

Figure 3. Iterative process of grounded theory in this study.

\subsection{Data Coding, Categorization, and Theory Building}

Data coding is the most important task to construct meaning from collected data in GTA [68]. Three steps are taken to eventually build a theory [69]: thematic analysis, generation of affinities or variables, and analysis of interrelationship digraph. In the thematic analysis phase, the process of identifying patterns within qualitative data is undertaken to discover the theme and further make sense of it [70]. Moreover, there should be three levels of coding [69] and constant comparative analysis for coding and category development through inductive processes [71]. Level 1 coding breaks the verbatim transcript into smaller basic, yet meaningful ideas, which leads to level 2 coding, and by comparing these small units of ideas, patterns can be identified accordingly. Since the interview questions of this research were designed to address specific research questions, 
theoretical rather than inductive thematic analysis was adopted [72]. Level 3 coding mainly focuses on systematically summarizing and organizing abstract constructs from themes extracted in level 2. Throughout the whole coding process, we followed Williams and Mosers's advice [68] that the researchers should "read and re-read interview transcriptions, field notes, and associated data sources involved in the data collection searching for thematic connectivity leading to thematic patterns."

Once the abstract constructs are recognized, the generation of affinities or variables is initiated and thematically defined clusters can then be labelled as affinities, which are elicited through a series of delicate examinations on the logic and meaning of analyzed themes. The last step of GTA is interrelationship digraph analysis, and the interrelationships between affinities linked through cross-examinations of the associative connotations and the direction of their relationship (i.e., which is the driver and which is the outcome) is determined based on the participants' comments [69]. These steps were iterative; as Charmaz [64] noted, "Data collection, analysis and resultant theory generation has a reciprocal relationship ... it requires a constant interplay between the researcher and the data." The application of grounded theory for theory building was undertaken in the following steps, which was in line with the method adopted by Soares and Oliveira [73]:

1. Transcribe the interviews and organize EFL learners' feedback about LMOOCs.

2. Identify the codes based on the interviewees' feedback.

3. Verify the definition of the main network between the codes.

4. Identify new codes for pros and cons of using LMOOCs for ESP learning.

5. Construct a new network between new codes and specific codes for use of LMOOCs.

6. Mark excerpts in the texts, referring to the interview transcripts with the new codes.

7. Identify common factors among codes.

8. Define the substance of EFL learners' viewpoints on LMOOCs, including advantages and disadvantages.

\section{Results}

\subsection{RQ 1: How Do You, Learners in Hospitality English Courses, Perceive Your Learning Experience with LMOOCs?}

Out of the 15 participants in this study, 12 considered their experience learning with LMOOCs to be positive and suggested that the learning platform was convenient and helpful for them. They considered that their learning experience with LMOOCs and other MOOCS were similar. Most of the positive statements on both types of MOOC were collected in the first or second focus group interviews; for instance:

I like to use LMOOCs very much. [An LMOOC] is more convenient then other elearning platforms because it has more functionalities (e.g., multimodal materials and opportunities to interact with other learners) than other e-learning platforms that I have used. (NM1-1)

Another participant in the same focus group supported this statement right after hearing it and raised some intriguing points stemming from his experience learning subject matter with the MOOC:

[O]h yes, I totally agree with him [NM1], the convenience of the MOOC is the main reason for me to use it. Nevertheless, there are more attributes which attracted me to use it. These attributes include [that it is] multimodal, open, easy to access, and, more importantly, it fits my unstable learning time, because I had a job at a hotel and I had to be on duty at different times. (NM2-1)

Participants in other focus groups expressed similar views. Most made positive statements about MOOCs in their first focus group meeting; however, from the second interview on, some participants (seven out of 15) started to express different views between LMOOCs and other MOOCs. For example, participants FC4 and FS3 said that they preferred in-person interaction because the service industry is a "people industry", and it is quite important for prospective workers to have interpersonal skills; equally impor- 
tant, interactions are also critical for language learning, particularly for communicative competence, which, these participants argued, would be hard to enrich with LMOOCs.

I have to admit that I like the flexibility of MOOCs. However, I found out that not being able to physically interact with others was the greatest drawback which could not be compensated [for] with convenience. (CF4-2)

Another participant expressed a similar opinion at another focus group meeting but tackled the issue from a different angle:

[T]he more I used MOOCs, I gradually realized something that MOOCs just could not function very well, which refers to the warmth and affection which a positive teacher-student relationship may harness to learning. (SM2-2)

While participant SM2-2 did not explicitly or directly mention that LMOOCs cannot provide the same benefits as physical interactions for language learning, he did point out that what is missing in MOOCs (for either language or other subjects) is teacher-student relationships. Another participant pointed out his concern that human learning might be reshaped by the technology:

I enjoy the convenience and usefulness of MOOCs, but I just feel that I should not be conditioned by the computer. (CM5-3)

Here, another downside common to LMOOCs and other MOOCs was raised by participant CM5-3; participant CF4 agreed with that and followed up:

I have to say that I have been kind of conditioned by MOOCs. Explicitly, I opened another window for the MOOC when I was at work and checked if there was anything going on or new feeds there. I don't know if it is good or bad, but it just turned out to be like this. (CF4-3)

In summary, participants shared their viewpoints about their personal learning experience with LMOOCs that differentiate them from other MOOCs. The major difference was not being able to enrich language learning through face-to-face interactions, a drawback that cannot be compensated for by the convenience of MOOCs. As for similarities, participants started with positive perceptions of both, mainly focused on convenience and flexibility. Nevertheless, after a while, some participants had concerns about (L)MOOCs and said they were worried about being conditioned by them, which meant that their lifestyles had been somewhat affected by (L)MOOCs. These participants tended to be too reliant on technology, and this situation implied that they might learn less effectively with traditional classroom instruction, where the ecosystem would be different.

\subsection{RQ2: What Are Your Underlying Reasons for Using LMOOCs to Learn Hospitality English?}

After identifying the participants' perceptions of using LMOOCs, we further aimed to understand the underlying reasons why they did or did not intend to continue using them. In various focus group interviews, participants who had positive perceptions focused on the convenience of LMOOCs and the diversity of participants that can be convened.

It is indeed very convenient to use LMOOCs to learn. On the other hand, some of my natural born abilities, e.g., my working memory capacity and attention span, seemed to vanish because of the convenience of MOOCs.... I did not need to remember some details taught by the instructor because all I had to do was to re-play the video clip or went back to the previous page. (SM2-2)

[O]ne of the impressive affordances of LMOOCs is that I had the chance to interact with others who I did not know and I felt really comfortable about it. (CF1-2)

Another participant pointed out that she generally appreciated the affordances of MOOCs but did not think it was a good idea to learn English via LMOOC: 
I will continue to use MOOCs to learn different subjects, but not hospitality English, because MOOCs lack one of the most essential aspects of hospitality English, face-to-face interaction. (SF1-2)

I believe that I will use LMOOCs in my future study of hospitality or English courses because it is really convenient to me, and to me, flexibility is everything because of my unusual schedule. (NM2-1)

Another participant, who did not speak often in the interviews, also commented on this question. Although she had been shy, she paid close attention to what the others were saying. She raised the following point:

I like LMOOCs and I will keep on using them in hospitality as well as other English courses because of my introverted personality. I feel more comfortable interacting with people in virtual environments. (SF4-3)

Participant SM2 stated that he would not use LMOOCs for the following reasons:

I don't think I will use MOOCs in the future because I think the instructor and other learners ignored my responses all the time. I don't know why, but I just logged off and have not used it after a few times of being ignored.... Being ignored in the virtual world also hurts. (SM2-2)

Participants SF4 and SF5 in the same group seemed to agree with him by nodding their heads. To confirm their meaning and understand their thinking, we asked a follow-up question: "What did you do if you were ignored by the instructor or your peers?" They responded as follows:

[W]ell, I understood that sometimes the instructor or other participants probably did not understand my questions or statement and therefore did not know how to make proper responses, so I felt quite all right. ... Nevertheless, I would feel much better if someone could respond to my questions or statements. (SF4-2)

I am not sure if I have had experience of being ignored by anyone in the LMOOC, but I just don't like that kind of feeling. (SF5-2)

Thus, overall, when participants were asked about the underlying reasons why they did or did not intend to continue learning with LMOOCs, positive reasons included the opportunity to interact with peers of various cultural and educational backgrounds, and that it enabled learners with introverted personalities or different learning styles to fit in. In terms of reasons not to continue, they noted that LMOOCs lack face-to-face interaction, which they considered to be the essence of language learning, and suggested that this would be the greatest downside for participants. Some of them also said that being ignored by instructors or peers was a reason not to continue. After considering the pros and cons of LMOOCs, nine of the 15 participants said they wished to continue using LMOOCs.

\subsection{RQ3: What Are the Biggest Benefits and Challenges You Have Encountered in Your Experience Using LMOOCs to Learn Hospitality English?}

Most participants talked about benefits in the first two focus interviews but gradually started to discuss the challenges they experienced in the last interview. For example, participants SF5 and NF4 talked about the benefits of LMOOCs in the first interview:

[T] he LMOOC was fantastic because I can retrieve any information about the subject matter anytime, anywhere, because they are just there and they never disappear as long as I have internet access. (SF5-1)

[T] me the greatest benefit about LMOOCs was that I can get to observe others' interactions and learn something from them. Other than this, I personally consider myself a slow learner and I have to take time to digest newly acquired information and I could take time with LMOOCs. (NF4-1) 
In the latter interviews, these two participants talked about challenges more than benefits, and intriguingly, the benefits they had previously mentioned turned out to involve strong challenges as well:

I am still fond of the convenience of LMOOCs, but somehow I felt it challenging for me to use it. ... The problem is not LMOOCs, but me. I got lazy way too easy and without [an] external driver. (SF5-3)

[A]s I mentioned before, I like to learn new things through observing others first, but the thing is that not so many participants [came to] interact via LMOOC gradually and therefore I had no one to observe. (NF4-2)

The benefit of LMOOCs that participants brought up in this round of interviews was that they were able to learn by observing others' interactions and disregard the affective filter they might have in a traditional class. On the other hand, the challenge they faced was that they had too much latitude with the LMOOC; unless they were extremely motivated, they would gradually drop out. After analyzing the qualitative data, a conceptual model of the applicability of MOOCs in hospitality English based on the framework analysis was developed (Figure 4).

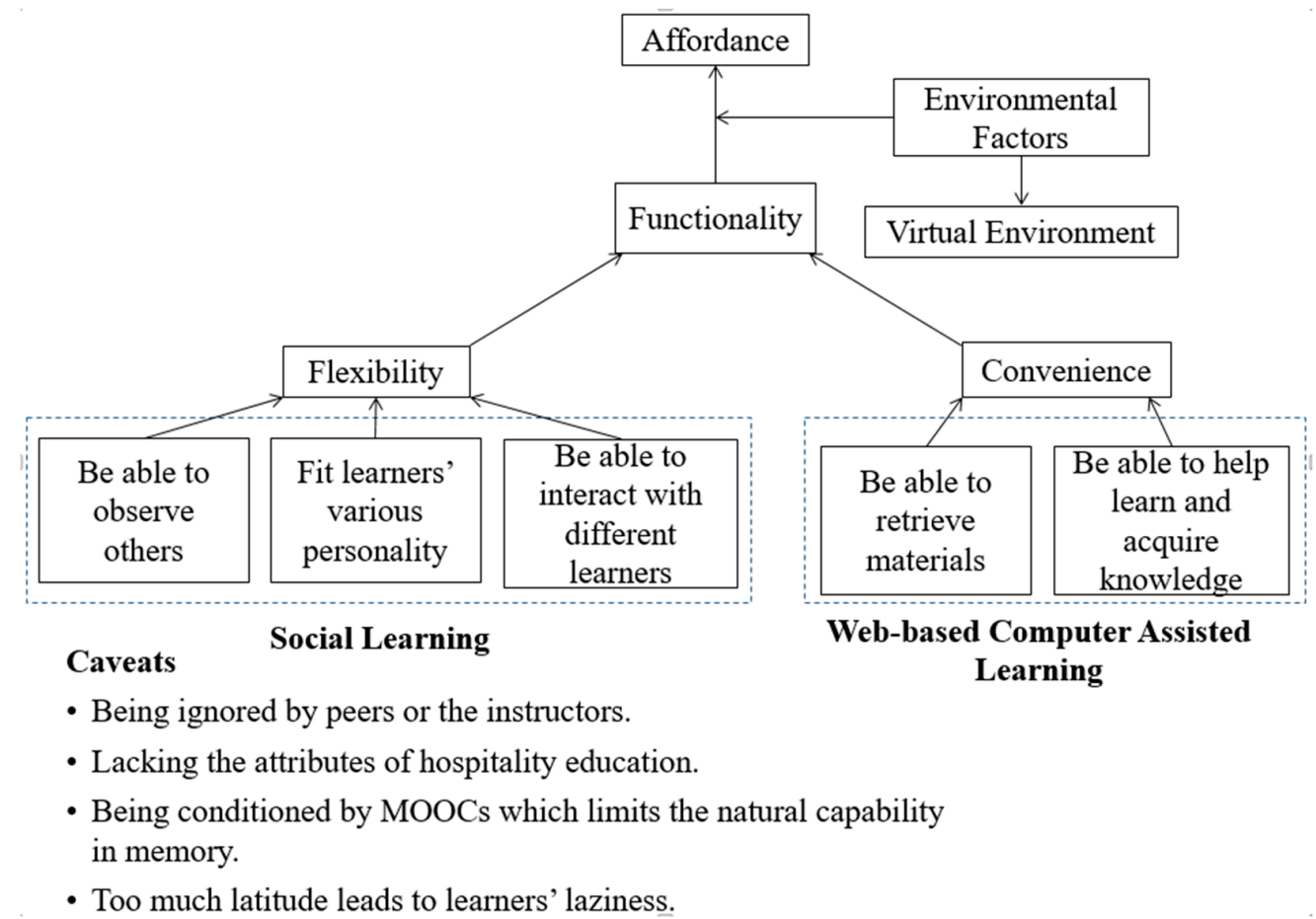

Figure 4. Conceptual model of applicability of MOOCs in hospitality English.

As shown in the model, the benefits of LMOOCs described by the participants are related to flexibility or convenience, both aspects of the platform's functionality. The concept of affordance refers to the relationship between a user and an object (here, a particular device or virtual environment) [74]. Given that this study reveals downsides, including a lack of face-to-face interaction and being ignored by peers or instructors, which may be easier to overcome in traditional classrooms through contextual cues or body language, the affordances of LMOOCs can only be fully appreciated when such environmental factors are taken into account along with functionality.

\section{Discussion, Limitations, and Implications}

The lack of a sound framework for institutions and practitioners hinders the development of MOOCs [75]. The present study was designed inductively to elicit insightful information about the applicability of LMOOCs. This study adopted grounded theory to 
interpret the data and identify issues faced by this underexplored learning platform. The results of the data analysis show some findings that deserve further discussion.

The findings of this study shed light on participants' viewpoints on their learning experience with LMOOCs, and both upsides and downsides were identified. Over half of the participants would continue to use LMOOCs for English language learning. This study further explores the reasons why they would or would not continue to use LMOOCs. Subsequently, we went on to investigate the benefits and challenges participants have encountered in their experience of using LMOOCs to learn English. The benefits participants mentioned in the interviews included the flexibility and convenience of LMOOCs, echoing a study by Schulze and Scholz [76]. Flexibility is an important factor in the sustainability of an online course [77], and in this study, it involved "making it possible to observe others," "fitting learners' various personalities," and "allowing interactions with different learners," items that reflect the theory of social learning [33,34,78]. In contrast, convenience items such as "allowing retrieval of materials" and "helping learners learn and acquire knowledge" are advantages of computer-assisted learning (CAL). CAL first appeared in the 1950s as computers were introduced to educational practice and can be defined as "learning procedures and environments facilitated through computers" [79] (p. 93). The rapid development of information communication technology has propelled CAL into a new web-based practice to improve the efficiency of learning [80]. Results of the present study on the convenience of LMOOCs reflect the advantages of web-based CAL [80,81].

Most participants agreed that the functionality of LMOOCs enabled them to learn under conditions of greatly reduced time and space, in line with the findings of Ryan et al. [82]. Such an advantage may be only partly perceived by today's learners, who are considered "digital natives," having grown up with technological savvy for the daily application of technical tools, and may, thus, take them for granted [83]. In this context, the ability of LMOOCs to disseminate knowledge in a virtual environment can be deemed a natural evolution of education. As Gaver [84] explained, the affordances of a specific technology are its inherent and important properties, and the aforementioned functionality provided by the virtual environment can, thus, be viewed as the key affordance of MOOCs [85].

Alongside the affordances, some downsides were also expressed by participants. For example, their interest in learning and/or their motivation to learn with LMOOCs seemed to wane after a few sessions. In this case, the lack of intimacy experienced in face-to-face interactions was the main reason for participants' lack of motivation; thus, MOOC designers would be well advised to include more collaborative activities [86] or combine pure LMOOCs with traditional classroom teaching, as suggested by Wang et al. [87], because it still seems to be challenging to create adequate socialization in a virtual environment [76].

However, when planning collaborative activities in MOOCs, participants' willingness to engage is another issue for discussion. In this study, some participants said they preferred to observe others on MOOCs but not actively engage, which echoes a rationale of the theory of social learning [38]. This preference stemmed from their personality traits or learning styles; they did not elaborate whether social identity was a barrier but did mention being ignored by the instructor or peers, and it remains to be clarified whether being ignored in this way was a result of their social identity. This study, thus, suggests that it is vital for MOOC instructors who wish to foster interactions to make sure that no students are isolated, because being ignored by others can activate the pain matrix of the brain $[88,89]$.

Another issue that was raised was whether observation itself can be considered a form of engagement in social interactions, in that learners will place themselves in the "silent period" when building up their own knowledge by listening and observing [23,90]. Future research on learners' engagement in LMOOCs could also take this issue into consideration. Furthermore, the issue of demotivation while learning a language in conventional learning contexts has been addressed by scholars such as Kikuchi [91] and Sasaki and Kikuchi [92]; whether this issue will be alleviated or exacerbated in LMOOCs might be an interesting topic for future investigation. 
At the same time, the effectiveness of learning through observing others on MOOCs makes it worth the effort to conduct further exploration. A study on memory and the adoption of the Internet indicated that when learners realize that the information they need is always there on the Internet and they do not need to dedicate effort to remember it, the cognitive consequences are drastic [93]. Some participants in the present study stated that one of the benefits of learning with MOOCs happened to be the affordance that the learning materials are always available on the platform. More empirical evidence will be needed to examine whether such an affordance will compensate for the above mentioned cognitive alteration.

In light of the present research, we call for such a shift globally and suggest that educational institutions assume social responsibility and collaborate with industry to provide further training for in-service employees; in this way, the cost of training will be reduced and the skills of hospitality professionals will improve [82]. This type of collaboration will generate mutual benefits for universities and industry; however, the high dropout rate of MOOCs inevitably makes the effectiveness of such courses questionable, and hence, their applicability remains debatable. Stracke [21] proposed a new perspective on the high dropout rate, suggesting that it reflects participants' diverse goals for taking a course; that is, at least some MOOC dropouts have achieved their learning goals in the course and do not need to stick around, and not just struggling or demotivated learners drop out.

Furthermore, a study conducted a decade ago by Woody et al. [94] indicated that students, regardless of their prior experience with computers and related technology, preferred printed textbooks over electronic versions. The development of education technology has changed drastically; hence, such a statement may not reflect the views of all students today. Nevertheless, traditional ways of teaching and learning still have something that cannot be replaced by technology; perhaps blended education, which integrates traditional instruction and technology, is more suitable for language learning [95]. Last but not least, the affordances of MOOCs may also cause some unexpected outcomes for learners; for example, MOOCs lead to laziness because they grant learners too much latitude in pursuing outcomes and completing assignments, lowering their motivation to finish the course. Moreover, some participants of this study also pointed out that their lifestyles were conditioned and cognitive abilities were reshaped by MOOCs. Future studies should explore these issues from the perspective of psychology and neuroscience in order to provide more diverse examinations of the applicability of MOOCs in hospitality English. Empirical evidence in recent studies [95-97] shows that in a blended model, online and face-to-face learning can complement each other and optimize the applicability of LMOOCs.

There are some limitations of the present study. The first limitation is that the variables of participants' characteristics as working people and the course as an ESP are not fully explored in this study. Many other dimensions, such as learners, instructors, courses, technology, design, and environment, could affect students' points of view on LMOOCs. Therefore, this study could not cover as many factors as possible, and it is advised that future studies include more factors for further exploration. Another limitation has to do with the generalizability of the results. As it is a qualitative study, the sample size is small, and caution is advised when the results of this study are generalized to include participants with various backgrounds.

\section{Conclusions}

Given that MOOCs have developed exponentially since the early 2010s, they have drawn much attention in academia. The present research was undertaken with the aim of exploring the applicability of LMOOCs in hospitality English. Fifteen participants went through four rounds of focus group interviews, and insightful information was extracted from saturated data. Two functions, flexibility and convenience, respectively, representing the areas of social learning and web-based computer-assisted learning, were inductively derived from participants' opinions through framework analysis. However, participants 
also revealed some downsides to the use of LMOOCs in hospitality English learning. Their statements about being ignored by peers and instructors and the lack of warmth from real face-to-face interactions are related to environmental factors that affect the successful implementation of web-based learning. This does not imply that these problems do not exist in traditional classrooms, but face-to-face instructors can use contextual cues or body language to address and ameliorate such issues. If LMOOC practitioners can come up with approaches or strategies to deal with such environmental factors, the affordances of LMOOCs will be fully activated.

Two other caveats should also be taken into account. First, one affordance of (L)MOOCs is that they do not require learners to memorize a great deal of information, as it is all stored online; therefore, learners' memorization and retention capacity may be changed by (L)MOOCs, and they may experience demotivation related to the lack of face-to-face interactions. These issues will need more empirical evidence, which can build on the approaches and findings of the present study.

This study makes the following contributions: First, it explored the applicability of LMOOCs in hospitality English through the lens of users' experiences and their intention to use MOOCs for future education. On this basis, pros and cons of using (L)MOOCs in hospitality courses were noted. Second, based on the data, a conceptual model of the applicability of LMOOCs in hospitality English was presented, incorporating important elements such as flexibility, convenience, functionality, and affordance. Finally, the rigorous design of this qualitative research depicts the phenomenon of EFL learners' viewpoints about LMOOCs with insightful information and enhances our understanding of this phenomenon, as stated by Williams and Moser [68].

Funding: The sources of funding for this study is the Ministry of Science and Technology, Taiwan (MOST 105-2511-S-328-001-MY2).

Institutional Review Board Statement: Not applicable.

Informed Consent Statement: Informed consent was obtained from all subjects involved in the study.

Data Availability Statement: Please contact the author for data requests.

Acknowledgments: The author would like to show his greatest appreciation for reviewers' constructive suggestions.

Conflicts of Interest: The author declares no conflict of interest.

\section{References}

1. Kop, R. The challenges to connectivist learning on open online networks: Learning experiences during a massive open online course. Int. Rev. Res. Open Distrib. Learn. 2011, 12, 19-38. [CrossRef]

2. Soares, F.; Lopes, A.P.; Vieira, I. Behind video lectures in a MOOC. In Proceedings of the Inted 2015 Proceedings, IATED, Valencia, Spain, 2-4 March 2015.

3. Tiryakioglu, F.; Erzurum, F. Use of Social Networks as an Educational Tool. Contemp. Educ. Technol. 2011, 2, 135-150. [CrossRef]

4. Jones, N.; Blackey, H.; FitzGibbon, K.; Chew, E. Get out of MySpace! Comput. Educ. 2010, 54, 776-782. [CrossRef]

5. Shadiev, R.; Hwang, W.-Y.; Huang, Y.-M. A pilot study: Facilitating cross-cultural understanding with project-based collaborative learning in an online environment. Australas. J. Educ. Technol. 2015, 31, 123-139. [CrossRef]

6. Joo, K.H.; Park, N.H. Cooperative Learning Strategy with a Mobile Environment. Int. J. Control. Autom. 2015, 8, 251-260. [CrossRef]

7. De Freitas, S.I.; Morgan, J.; Gibson, D. Will MOOCs transform learning and teaching in higher education? Engagement and course retention in online learning provision. Br. J. Educ. Technol. 2015, 46, 455-471. [CrossRef]

8. Uchidiuno, J.O.; Ogan, A.; Yarzebinski, E.; Hammer, J. Going Global: Understanding English Language Learners' Student Motivation in English-Language MOOCs. Int. J. Artif. Intell. Educ. 2017, 28, 528-552. [CrossRef]

9. Friðriksdóttir, K. The impact of different modalities on student retention and overall engagement patterns in open online courses. Comput. Assist. Lang. Learn. 2017, 31, 1-19. [CrossRef]

10. Sokolik, M. What Constitutes an Effective Language MOOC. In Language MOOCs: Providing Learning, Transcending Boundaries; De Gruyter Open: Warsaw, Poland, 2015; pp. 16-32.

11. Cadwalladr, C. Do Online Courses Spell the End for the Traditional University? The Observer. Available online: http://www. guardian.co.uk/education/2012/nov/11/online-free-learning-end-of-university (accessed on 11 November 2012). 
12. Alraimi, K.M.; Zo, H.; Ciganek, A.P. Understanding the MOOCs continuance: The role of openness and reputation. Comput. Educ. 2015, 80, 28-38. [CrossRef]

13. Voss, B.D. Massive Open Online Courses (MOOCs): A Primer for University and College Board Members. Association of Governing Boards of Universities and Colleges. 2013. Available online: http://agb.org/sites/agb.org/files/report_2013_MOOCs. pdf (accessed on 4 April 2020).

14. Romeo, K. Language learning MOOCs. Hive Talkin. 2012. Available online: https://web.stanford.edu/group/ats/cgi-bin/ hivetalkin/?p=3011 (accessed on 27 January 2019).

15. Jackson, N. On MOOCs and Some Futures for Higher Education. 2013. Available online: http://noelbjackson.wordpress.com/20 13/06/01/on-moocs-and-some-possible-futures-forhigher-ed/ (accessed on 21 December 2019).

16. Daniel, J. Making Sense of MOOCs: Musings in a Maze of Myth, Paradox and Possibility. J. Interact. Media Educ. 2012, 2012, 18. [CrossRef]

17. Hood, N.; Littlejohn, A.; Milligan, C. Context counts: How learners' contexts influence learning in a MOOC. Comput. Educ. 2015, 91, 83-91. [CrossRef]

18. Jordan, K. Initial trends in enrolment and completion of massive open online courses. Int. Rev. Res. Open Distrib. Learn. 2014, 15. [CrossRef]

19. Kolowich, S. The professors who make the MOOCs. Chron. High. Educ. 2013, 25. Available online: http:/ / publicservicesalliance. org/wp-content/uploads/2013/03/The-Professors-Behind-the-MOOC-Hype-Technology-The-Chronicle-of-Higher-Education. pdf (accessed on 28 September 2020).

20. Reich, J. Rebooting MOOC Research. Science 2015, 347, 34-35. [CrossRef] [PubMed]

21. Stracke, C.M. Why We Need High Drop-Out Rates in MOOCs: New Evaluation and Personalization Strategies for the Quality of Open Education. In Proceedings of the 2017 IEEE 17th International Conference on Advanced Learning Technologies (ICALT), Timisoara, Romania, 3-7 July 2017; pp. 13-15.

22. Jung, Y.; Lee, J. Learning Engagement and Persistence in Massive Open Online Courses (MOOCS). Comput. Educ. 2018, 122, 9-22. [CrossRef]

23. Martín-Monje, E.; Castrillo, M.D.; Mañana-Rodríguez, J. Understanding online interaction in language MOOCs through learning analytics. Comput. Assist. Lang. Learn. 2018, 31, 251-272. [CrossRef]

24. Kizilcec, R.F. Collaborative learning in geographically distributed and in-person groups. In Proceedings of the AIED 2013 Workshops, Memphis, TN, USA, 9-13 July 2013.

25. Veletsianos, G.; Collier, A.; Schneider, E. Digging deeper into learners' experiences in MOOCs: Participation in social networks outside of MOOCs, notetaking and contexts surrounding content consumption. Br. J. Educ. Technol. 2015, 46, 570-587. [CrossRef]

26. Saputro, R.E.; Salam, S.; Zakaria, M.H.; Anwar, T. A gamification framework to enhance students' intrinsic motivation on MOOC. Telkomnika Telecommun. Comput. Electron. Control. 2019, 17, 170-178. [CrossRef]

27. Bandura, A. Self-efficacy: Toward a unifying theory of behavioral change. Psychol. Rev. 1977, 84, 191-215. [CrossRef]

28. Tu, C.-H. On-line learning migration: From social learning theory to social presence theory in a CMC environment. J. Netw. Comput. Appl. 2000, 23, 27-37. [CrossRef]

29. Brown, J.S.; Adler, R.P. Open education, the long tail, and learning 2.0. Educause Rev. 2008, 43, 16-20.

30. Spencer, R. How to Apply Social Learning Theory for Effective E-Learning. 2015. Available online: https://trainingindustry.com/ press-release/strategy-alignment-and-planning/2015-training-industry-editorial-award-nominations-announced/ (accessed on 1 December 2019).

31. Hill, P. Emerging Student Patterns in MOOCs: A (Revised) Graphical View. Available online: http://mfeldstein.com/emergingstudent-patterns-in-moocs-a-revised-graphicalview (accessed on 1 December 2019).

32. Anderson, A.; Huttenlocher, D.; Kleinberg, J.; Leskovec, J. Engaging with massive online courses. In Proceedings of the 23rd International Conference on Real Time and Networks Systems, Seoul, Korea, 7-11 April 2014; Association for Computing Machinery (ACM): New York, NY, USA, 2014; pp. 687-698.

33. Miller, M.T.; Lu, M.-Y. Serving non-traditional students in e-learning environments: Building successful communities in the virtual campus. Educ. Media Int. 2003, 40, 163-169. [CrossRef]

34. Clerehan, R.; Turnbull, J.; Moore, T.; Brown, A.; Tuovinen, J. Transforming Learning Support: An Online Resource Centre for a Diverse Student Population. Educ. Media Int. 2003, 40, 15-32. [CrossRef]

35. Thomas, J.W. A Review of Research on Project-Based Learning. Autodesk. 2003. Available online: https://documents.sd61 bc.ca/ANED/educationalResources/StudentSuccess / A_Review_of_Research_on_Project_Based_Learning.pdf (accessed on 1 December 2019).

36. Peterson, M. Computerized Games and Simulations in Computer-Assisted Language Learning: A Meta-Analysis of Research. Simul. Gaming 2009, 41, 72-93. [CrossRef]

37. Ruey, S. A case study of constructivist instructional strategies for adult online learning. Br. J. Educ. Technol. 2009, 41, 706-720. [CrossRef]

38. Goodyear, P. Educational design and networked learning: Patterns, pattern languages and design practice. Australas. J. Educ. Technol. 2005, 21, 82-101. [CrossRef] 
39. Murugaiah, P.; Atan, H.; Samsudin, D.; Idrus, R. The web-based learning environment: A comparative study between the constructivist and content-based approaches. In Proceedings of the Fourth IEEE International Conference on Advanced Learning Technologies (ICAT), Piscataway, NJ, USA, 30 August 2004.

40. Bárcena, E.; Read, T.; Martín-Monje, E.; Castrillo, M.D. Analysing student participation in Foreign Language MOOCs: A case study. Emoocs Eur. Moocs Stakehold. Summit 2014, 11-17. Available online: https://www.researchgate.net/profile/AnjaLorenz/publication/263543544_Open_Online_Courses_in_the_context_of_higher_education_an_evaluation_of_a_German_ cMOOC/links/54941c560cf2e1b6095f97bc/Open-Online-Courses-in-the-context-of-higher-education-an-evaluation-of-aGerman-cMOOC.pdf\#page=11 (accessed on 15 December 2020).

41. Ding, Y.; Shen, H. Delving into learner autonomy in an EFL MOOC in China: A case study. Comput. Assist. Lang. Learn. 2019, 1-23. [CrossRef]

42. Perifanou, M. Personalized MOOCs for language learning: A challenging proposal. Elearning Pap. 2015, 45, 4-16.

43. Beirne, E.; Mhichíl, M.N.G.; Cleircín, G.Ó. LMOOCs, classifying design: Survey findings from LMOOC providers. In CALL in a Climate of Change: Adapting to Turbulent Global Conditions; Research-publishing.net: Voillans, France, 2017; pp. 30-34. [CrossRef]

44. Martín-Monje, E.; Read, T.; Barcena, E. The Importance of Forum Interaction and Success Rates in Language MOOCs. In Proceedings of the EMOOCs 2017, Madrid, Spain, 22-26 May 2017; pp. 10-15.

45. Fuchs, C. 'It's a Humbling Experience'-Lessons from Language MOOCs. European Journal of Open, Distance and E-learning. Available online: http:/ / www.eurodl.org/index.php? $\mathrm{p}=$ current\&sp=brief\&article=738 (accessed on 28 November 2018).

46. Perifanou, M.; Economides, A. MOOCS for foreign language learning: An effort to explore and evaluate the first practices. MOOCs for Language Learning: An effort to explore and evaluate the first practices. In Proceedings of the INTED2014 Conference, Valencia, Spain, 8-12 March 2014. Available online: http://library.iated.org/view/PERIFANOU2014MOO (accessed on 11 November 2018).

47. Panagiotidis, P. MOOCs for language learning. Reality and prospects. In Proceedings of the Society for Information Technology \& Teacher Education International Conference, Las Vegas, NV, USA, 18 March 2019; Graziano, K., Ed.; Association for the Advancement of Computing in Education (AACE): Las Vegas, NV, USA, 2019; pp. 540-546. Available online: https://www. learntechlib.org/primary/p/207692/ (accessed on 1 December 2019).

48. Scholz, K.; Schulze, M. Digital-gaming trajectories and second language development. Lang. Learn. Technol. 2017, $21,100-120$.

49. Martín-Monje, E.; Bárcena, E.; Read, T. Exploring the affordances of Massive Open Online Courses on second languages. In Proceedings of the UNED-ICDE (International Council for Open and Distance Education), UNED, Madrid, Spain, 28 January 2013.

50. Martín-Monje, E.; Barcena, E. (Eds.) Language MOOCs: Providing Learning, Transcending Boundaries; De Gruyter Open: Berlin, Germany, 2015.

51. Karpouza, E.; Emvalotis, A. Exploring the teacher-student relationship in graduate education: A constructivist grounded theory. Teach. High. Educ. 2018, 24, 121-140. [CrossRef]

52. Noble, H.; Mitchell, G. What is grounded theory? EÉvid. Based Nurs. 2016, 19, 34-35. [CrossRef]

53. Glaser, B.G.; Straus, A.L. The Discovery of Grounded Theory; Aldine: Chicago, IL, USA, 1967.

54. Aldiabat, K.M.; Navenec, L. Data saturation: The mysterious step in grounded theory method. Qual. Rep. 2018, $23,245-261$.

55. Charmaz, K. Grounded Theory: Objectivist and constructivist methods. In Handbook of Qualitative Research, 2nd ed.; Norman, K.D., Yvonne, S.L., Eds.; Sage: London, UK, 2000.

56. Nyumba, T.O.; Wilson, K.; Derrick, C.J.; Mukherjee, N. The use of focus group discussion methodology: Insights from two decades of application in conservation. Methods Ecol. Evol. 2018, 9, 20-32. [CrossRef]

57. Krueger, R.A.; Casey, M.A. Focus Groups: A Practical Guide for Applied Research; Sage Publications: Thousand Oaks, CA, USA, 2014.

58. Onwuegbuzie, A.J.; Leech, N.L. A Call for Qualitative Power Analyses. Qual. Quant. 2007, 41, 105-121. [CrossRef]

59. Chenitz, C.W.; Swanson, J.M. From Practice to Grounded Theory: Qualitative Research in Nursing; Addison-Wesley: Menlo Park, CA, USA, 1986.

60. Cunningham, N.; Carmichael, T. Sampling, interviewing and coding: Lessons from a constructivist grounded theory study. In Proceedings of the European Conference on Research Methodology for Business and Management Studies, Dublin, Ireland, 22-23 June 2017; pp. 78-85.

61. Orland-Barak, L. The Theoretical Sensitivity of the Researcher: Reflections on a complex construct. Reflective Pract. 2002, 3, 263-278. [CrossRef]

62. Weed, M. Research quality considerations for grounded theory research in sport \& exercise psychology. Psychol. Sport Exerc. 2009, 10, 502-510. [CrossRef]

63. Lawrence, J.; Tar, U. The use of grounded theory technique as a practical tool for qualitative data collection and analysis. Electron. J. Bus. Res. Methods 2013, 11, 29-40.

64. Charmaz, K. Constructing Grounded Theory: A Practical Guide through Qualitative Analysis; Sage: Los Angeles, CA, USA, 2006.

65. Glaser, B.G.; Straus, A.L. Status Passage: A Formal Theory; Aldine: Chicago, IL, USA, 1971.

66. Morse, J.M. Qualitative Health Research. Qual. Health Res. 2016, 25, 587-588. [CrossRef]

67. O'Reilly, M.; Parker, N. 'Unsatisfactory Saturation': A critical exploration of the notion of saturated sample sizes in qualitative research. Qual. Res. 2012, 13, 190-197. [CrossRef]

68. Williams, M.; Moser, T. The art of coding and thematic exploration in qualitative research. Int. Manag. Rev. 2019, 15, 45-55. 
69. Yan, J.X.; Horwitz, E.K. Learners' Perceptions of How Anxiety Interacts With Personal and Instructional Factors to Influence Their Achievement in English: A Qualitative Analysis of EFL Learners in China. Lang. Learn. 2008, 58, 151-183. [CrossRef]

70. Maguire, M.; Delahunt, B. Doing a thematic analysis: A practical, step-by-step guide for learning and teaching scholars. AISHE-J All Irel. J. Teach. Learn. High. Educ. 2017, 9, 3351-3514.

71. Tie, Y.C.; Birks, M.; Francis, K. Grounded theory research: A design framework for novice researchers. Sage Open Med. 2019, 7, 1-8. [CrossRef]

72. Braun, V.; Clarke, V. Using thematic analysis in psychology. Qual. Res. Psychol. 2006, 3, 77-101. [CrossRef]

73. Soares, E.; Oliveira, S. Application of Open Coding using the Grounded Theory Method to Identify the Profile of Information and Commucation Technology Companies in the State of Pará from Brazil. In ICSOFT; Springer: Prague, Czech Republic, 2019; pp. 194-201.

74. Conole, G.; Dyke, M. Understanding and using technological affordances: A response to Boyle and Cook. ALT-J 2004, 12, 301-308. [CrossRef]

75. Ng'Ambi, D.; Bozalek, V. Editorial: Massive open online courses (MOOCs): Disrupting teaching and learning practices in higher education. Br. J. Educ. Technol. 2015, 46, 451-454. [CrossRef]

76. Schulze, M.; Scholz, K. Learning trajectories and the role of online courses in a language program. Comput. Assist. Lang. Learn. 2017, 31, 185-205. [CrossRef]

77. Hjeltnes, T.; Horgen, S.A. Factors Influencing the Sustainability of MOOCs Compared with Traditional Distance Education Courses. In Proceedings of the Computer Vision, Rome, Italy, 26-29 October 2016; Springer International Publishing: Cham, Switzerland, 2016; Volume 10013, pp. 123-127.

78. Samson, P.L. Fostering Student Engagement: Creative Problem-Solving in Small Group Facilitations. Collect. Essays Learn. Teach. 2015, 8, 153-164. [CrossRef]

79. Schittek, M.; Mattheos, N.; Lyon, H.C.; Attström, R. Computer assisted learning. A Review. Eur. J. Dent. Educ. 2001, 5, 93-100. [CrossRef]

80. Sharma, R. Computer assisted learning-A study. Computer 2017, 4, 102-105.

81. Tareef, A.B. The effects of computer-assisted learning on the achievement and problem solving skills of the educational statistics students. Eur. Sci. J. 2014, 10, 271-279.

82. Ryan, P.; Horton-Tognazzini, L.; Williams, A. A Snapshot of MOOCs in Hospitality and Tourism. J. Hosp. Tour. Educ. 2016, 28, 107-112. [CrossRef]

83. Prensky, M. Digital Natives, Digital Immigrants Part 1. Horizon 2001, 9, 1-6. [CrossRef]

84. Gaver, W.W. Technology affordances. In Proceedings of the ACM SIGCHI Conference on Human Factors in Computing Systems, New Orleans, LA, USA, 27 April 1991; pp. 79-84.

85. Kreijns, K.; Kirschner, P.A.; Jochems, W. The sociability of computer-supported collaborative learning environments. Educational Technology \& Society. 2002, 5, 8-22.

86. Lin, J.; Cantoni, L.; Murphy, J. MOOCs in tourism and hospitality: A review. J. Teach. Travel Tour. 2018, 18, 217-235. [CrossRef]

87. Wang, J.; An, N.; Wright, C. Enhancing beginner learners' oral proficiency in a flipped Chinese foreign language classroom. Comput. Assist. Lang. Learn. 2018, 31, 490-521. [CrossRef]

88. Eisenberger, N.I.; Lieberman, M.D. Why rejection hurts: A common neural alarm system for physical and social pain. Trends Cogn. Sci. 2004, 8, 294-300. [CrossRef]

89. Restak, R. The Naked Brain: How the Emerging Neurosociety is Changing How We Live, Work, and Love; Crown Publishing Group: New York, NY, USA, 2009.

90. VanPatten, B.; Benati, A.G. Key Terms in Second Language Acquisition; Continuum: London, UK, 2010.

91. Kikuchi, K. Motivation and demotivation over two years: A case study of English language learners in Japan. Stud. Second. Lang. Learn. Teach. 2019, 9, 157-175. [CrossRef]

92. Sakai, H.; Kikuchi, K. An analysis of demotivators in the EFL classroom. System 2009, 37, 57-69. [CrossRef]

93. Sparrow, B.; Liu, J.; Wegner, D.M. Google Effects on Memory: Cognitive Consequences of Having Information at Our Fingertips. Science 2011, 333, 776-778. [CrossRef] [PubMed]

94. Woody, W.D.; Daniel, D.B.; Baker, C.A. E-books or textbooks: Students prefer textbooks. Comput. Educ. 2010, 55, 945-948. [CrossRef]

95. Karaaslan, H.; Kılı̧̧, N. Students' attitudes towards blended language courses: A case study. Dil Ve Dilbilimi Çalışmaları Derg. 2019, 15, 174-199. [CrossRef]

96. Du, W.; Wang, Y. Developing an Outcome-Based ESP Course with Blended-Learning Method for Chinese Undergraduates. Creat. Educ. 2019, 10, 1834-1849. [CrossRef]

97. Pikhart, M.; Klimova, B. Utilization of Linguistic Aspects of Bloom's Taxonomy in Blended Learning. Educ. Sci. 2019, 9, 235. [CrossRef] 